\title{
Effects of spinal cord stimulation on myocardial ischaemia during daily life in patients with severe coronary artery disease
}

\section{A prospective ambulatory electrocardiographic study}

Mike J L de Jongste, Jaap Haaksma, Raymond W M Hautvast, Hans L Hillege, Pim W J Meyler, Michiel J Staal, John E Sanderson, K I Lie

Departments of
Cardiology,
Anaesthesiology, and
Neurosurgery,
Thoraxcenter,
University Hospital of
Groningen, The
Netherlands
M J L de Jongste
J Haaksma
R W M Hautvast
H L Hillege
P W J Meyler
M J Staal
K I Lie
Department of
Cardiology, Taunton
and Somerset
Hospital, Taunton,
Somerset
J E Sanderson
Correspondence to:
Dr Mike J L de Jongste,
Department of Cardiology,
Thoraxcenter, University
Hospital of Groningen,
PO Box 30.001,
9700 RB Groningen,
The Netherlands.
Accepted for publication
11 October 1993

\section{Abstract}

Background-Spinal cord stimulation (SCS) may be a useful additional therapy for pain in patients with therapeutically refractory angina pectoris. But doubts remain about whether it also relieves ischaemia.

Methods-Indices of ischaemia were studied with and without SCS in 10 patients with otherwise intractable angina and evidence of myocardial ischaemia on $48 \mathrm{~h}$ ambulatory electrocardiographic (ECG) recording. Primary end points assessed by $48 \mathrm{~h}$ ECG recordings were total ischaemic burden, number of ischaemic episodes, and duration of ischaemic episodes. In addition, symptoms were assessed by a diary of glyceryl trinitrate intake and anginal attacks.

Results-During SCS the total ischaemic burden of the entire group was significantly reduced from a median of 27.9 $(1 \cdot 9-278 \cdot 2)$ before SCS to $0(0-70 \cdot 2)$ mm $\times$ min with SCS $(p<0.03)$. In six out

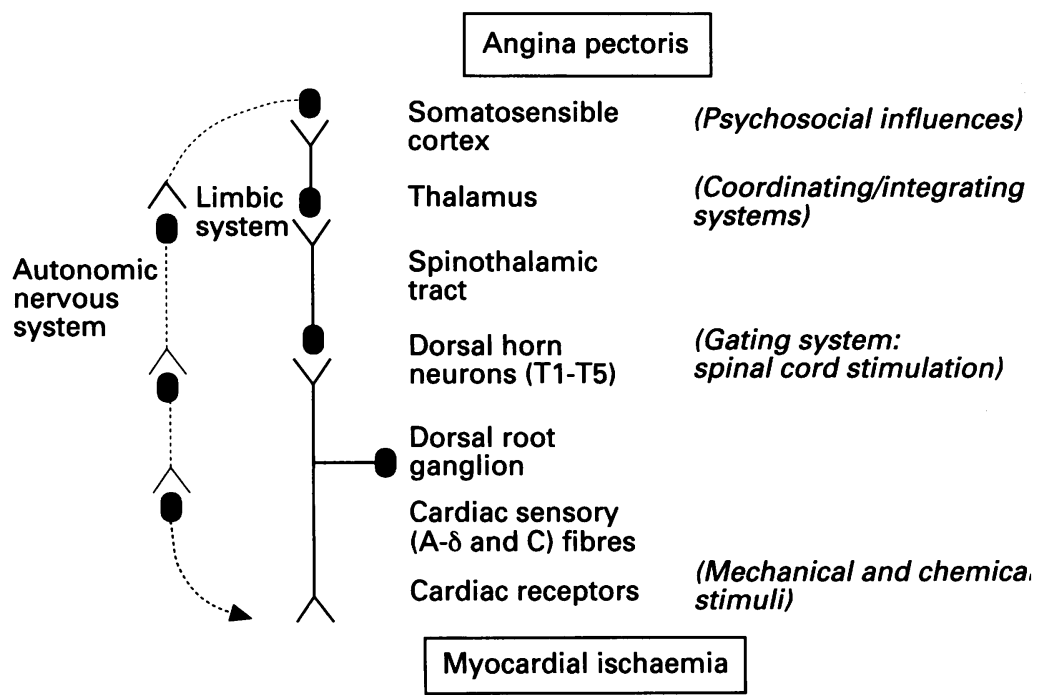

Figure 1 Simplified diagram of the sensory (afferent) and the efferent cardiac neural pathways. Myocardial ischaemia can stimulate both chemical and mechanical cardiac receptors. These receptors can elicit impulses in the sensory cardiac nerves. These sensory fibres enter the dorsal spinal cord at T1-T5 level where they connect with neurons. According to the gate control theory these impulses can be modulated by descending and other impulses. The spinothalamic tract relays impulses to the thalamus and the limbic system. Cardiac sensory impulses are further modulated in the higher brain centres, for example by the emotions. The limbic system is of paramount importance in the modulation of pain perception. Pain is perceived in the somatosensible cortex. Through these neuronal mechanisms, at different levels in the brain, visceral nociceptive stimuli can induce autonomic reactions such as a change in heart rate. of the 10 patients there was no myocardial ischaemia during $48 \mathrm{~h}$ ambulatory ECG monitoring with SCS. The number of ischaemic episodes was reduced from a median of $3(1-15)$ before SCS to $0(0-9)$ with SCS $(p<0 \cdot 04)$. The duration of ischaemic episodes decreased from a median of $20.6(1 \cdot 7-155 \cdot 4) \mathrm{min}$ before SCS to $0(0-48 \cdot 3)$ min with SCS $(p<0 \cdot 03)$. This was accompanied by a significant improvement in symptoms with a reduction in daily glyceryl trinitrate intake from a median of 3.0 (0-10) before SCS to $0.3(0-10)$ tablets per $48 \mathrm{~h}(\mathrm{p}<0.02)$ and a decrease in the frequency of anginal attacks from a median of $5 \cdot 5(2-14)$ before SCS to 1.0 (0-10) per $48 \mathrm{~h}$ with SCS (p < 0.03).

Conclusions-SCS not only reduced symptoms but also myocardial ischaemia. Therefore, SCS appears to be both a safe and an effective therapy for patients with refractory angina.

(Br Heart f 1994;71:413-418)

The gate control theory, which is the most popular hypothesis to explain the mechanism of action of neurostimulation as a treatment for pain, ${ }^{1}$ is based on the concept that impulse transmission in the small $\mathrm{C}$ pain fibres of the central nervous system can be inhibited by stimulation of the large non-nociceptive A fibres. The A fibres can be stimulated by an implantable device that activates sensory structures in the dorsal spinal cord (fig 1). This so-called spinal cord stimulation (SCS) has been successfully used since $1967,{ }^{23}$ mainly for patients with chronic pain syndromes. ${ }^{4}$

In the past decade SCS has been advocated as an additional therapy for patients with intractable angina pectoris ${ }^{5-7}$ to reduce or suppress cardiac pain in patients and increase exercise capacity. SCS reduced myocardial ischaemia during exercise testing, ${ }^{89}$ but does it have a beneficial effect on myocardial ischaemia during daily life?

We used $48 \mathrm{~h}$ ambulatory electrocardiographic (ECG) monitoring to evaluate the effect of intermittent SCS therapy on myocardial ischaemia during normal activity. 
Patients and methods

SELECTION OF PATIENTS

Patients with angina that was unresponsive to standard treatment were considered for SCS treatment and those who had ischaemia during ambulatory ECG monitoring before SCS were included in the study. The patients were on optimal antianginal treatment, including maximal tolerated dosages of $\beta$ blockers, calcium antagonists, and long-acting nitrates. Except for glyceryl trinitrate, medication was kept constant during the study. The study was approved by the hospital ethics committee.

AMBULATORY ECG MONITORING

We obtained $48 \mathrm{~h}$ ambulatory ECG recordings at baseline before SCS. After implantation of the SCS device we repeated $48 \mathrm{~h}$ ambulatory ECG monitoring in all patients. The electrodes connected to the ambulatory ECG tape recorder were secured to the chest

A

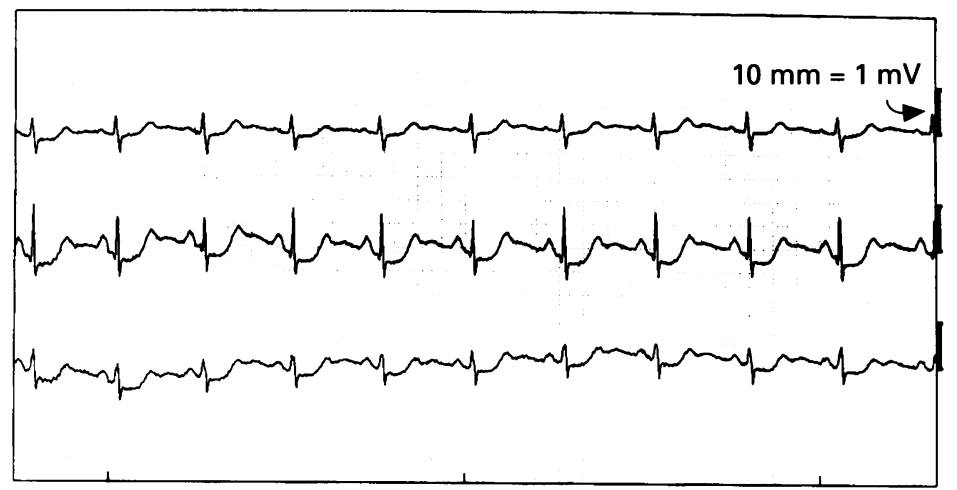

B

C
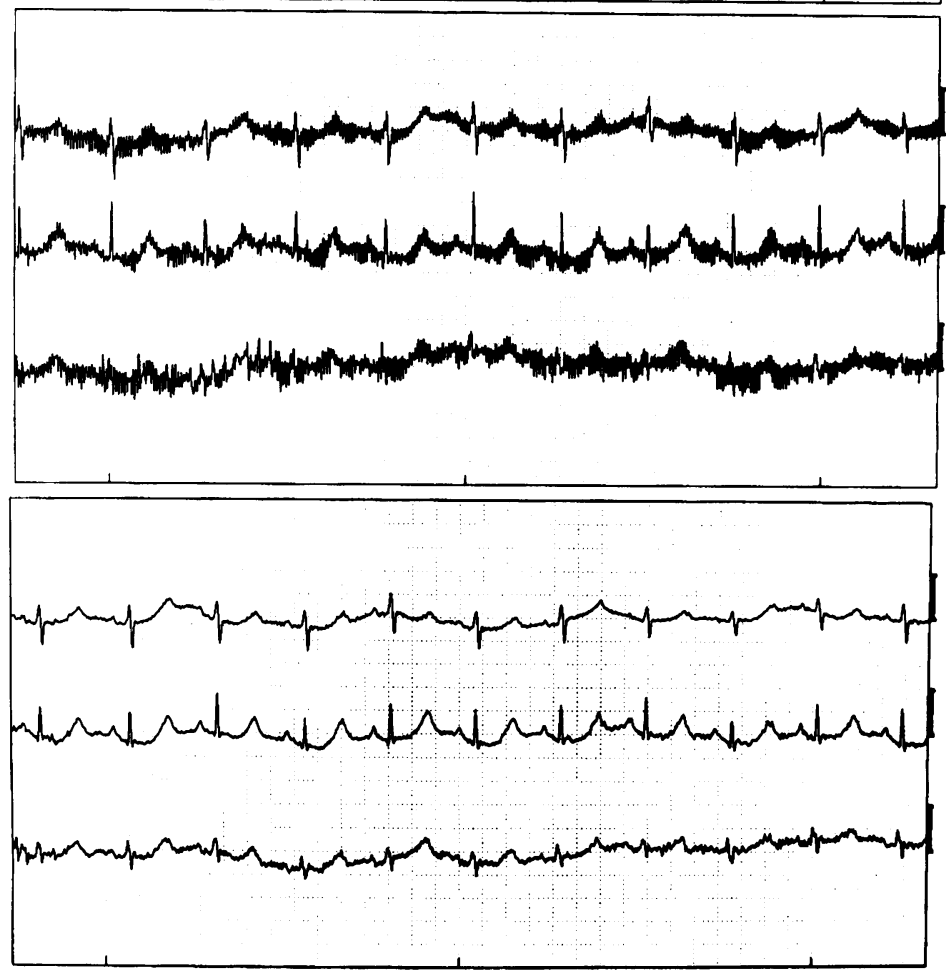

Figure 2 (A) Three channel ambulatory ECG before implantation (patient 4) (Paper speed $25 \mathrm{~mm} / \mathrm{s}$ ). All ECG recordings were taken from the same patient during heavy exercise. During all ambulatory ECG recordings the maximum recorded heart rate of this patient, who was taking $\beta$ blockers and calcium antagonists, was 94 beats per min. During this ECG tracing only did the patient have angina. (B) Three channel ambulatory ECG during SCS before filtering of SCS artefacts. An Itrell II with quadripolar electrodes was implanted. Note the SCS artefacts. The recording was obtained at about the same heart rate as in A. (C) Three channel ambulatory ECG tracing after filtering the SCS artefacts. in hospital. The ambulatory ECG recordings were obtained at home, and patients continued with their usual activities.

The primary end points were ischaemic indices assessed by $48 \mathrm{~h}$ ambulatory ECG recording (number and duration of ischaemic episodes and total ischaemia burden) and symptomatic ischaemia assessed by anginal attacks and glyceryl trinitrate intake scored in a $48 \mathrm{~h}$ diary during monitoring. Secondary end points were heart rates (minimum, average, and maximum), arrhythmias, and heart rate variability (HRV).

The electrodes were applied in the best position to show ST segment changes. We used the following leads: modified aVF, V1, and V5. We used the same electrode positions for all recordings in individual patients. Three-channel amplitude-modulated Marquette recorders were used (series 8500). A fourth channel recorded a $32 \mathrm{~Hz}$ time signal, which was used in a phase-locked loop circuit (as well as a timer for the AD converter) to correct for tape speed irregularity.

The ECG was analysed on Marquette XP analyser (software version 5.8) and reviewed by an experienced analyst who was supervised by a cardiologist. ST changes caused by posture were eliminated. We corrected for preexisting ST segment deviation by computing the ST segment as a moving average over $9 \cdot 5 \mathrm{~h}$. Each episode of at least $0 \cdot 1 \mathrm{mV}$ of horizontal or downsloping ST depression at $60 \mathrm{~ms}$ after the $\mathrm{J}$ point, lasting for at least a minute, and separated from another episode by at least a minute of normal ST segment was regarded as an ischaemic episode. ${ }^{1011}$

Because the characteristics of the default Marquette filter did not eliminate interference from stimulation artefacts on the surface ECG registrated by the ambulatory ECG recorder, we built in Krohn-Hite-tunable active filters (KH 3340) in low pass mode (for all three ECG channels separately) between the acquisition module and the ECG analyser.

In a pilot study in four patients we recorded ischaemic periods during $48 \mathrm{~h}$ ambulatory ECG monitoring by manual scoring before and during low pass filtering to see whether the filter influenced changes in ST segment. The filters had no demonstrable effect on ST segment change (fig 2). The low pass filters were set at a $-3 \mathrm{~dB}$ cut off point of $50 \mathrm{~Hz}(48$ $\mathrm{dB}$ octave for each channel with linear phase characteristics).

HRV was determined by fast Fourier analysis with standard Marquette software. In addition, to exclude the influence of heart rate on HRV, the fractional power measured in normalised units (nu) was calculated as the percentage of low frequency (LF) or high frequency $(\mathrm{HF})$ of the total power (TP). This coefficient of variance $(\mathrm{CV})$ was computed by dividing the square root of TP $(0 \cdot 01-1 \mathrm{~Hz})$ by the square root of LF $(0.04-0.15 \mathrm{~Hz})$ or HF $(0 \cdot 15-0.4 \mathrm{~Hz})$ respectively.

SURGICAL PROCEDURE FOR IMPLANTATION

The same neurosurgeon implanted all the SCS devices. Because correct positioning of 
the epidural electrode depends on the patient identifying the area of paresthesia during stimulation the surgical procedure must be performed under local anaesthesia. Because of these patients have heart disease we recommend that this part of the procedure should be supervised by an anaesthetist.

With the patient prone a small incision was made in the midline at the T4-T5 level. A Tuohy needle was used to puncture the epidural space. Under fluoroscopic control a lead (either a unipolar Pisces Sigma or a quadripolar Quad (Medronic, Minneapolis, $M N$, USA)) was inserted through this needle in the dorsal epidural space. The proximal electrode of the lead was positioned at the $\mathrm{C} 7$ level and the distal end of the lead was temporarily connected to an external stimulator. The electrode was withdrawn slightly to determine position of the electrode tip (mostly at T1 and slightly left from the midline) when paresthesia was elicited by the external stimulator. The paresthesia had to be provoked in the area where the patient usually felt angina. When the electrode was correctly positioned it was sutured into place and a left subcostal retrofascial pocket was created. An Itrell I (for unipolar stimulation) or an Itrell II pulse generator (Medronic, Minneapolis; $\mathrm{MN}, \mathrm{USA}$ ) (in patients with a quadripolar electrode) was placed in this pocket and attached to the epidural electrode by an extension lead in a subcutaneous tunnel.

STIMULATION PROTOCOL

All patients were allowed to use SCS (frequency of $85 \mathrm{~Hz}$ and duration of $210 \mu \mathrm{s}$ ) for an hour, three times per day and during angina attacks. The intensity was adjusted to the patient's needs and the amount of time stimulation was used was measured by telemetric analysis of the device at follow up visits.

\section{STATISTICAL ANALYSIS}

Statistical analysis was performed by SPSS/PC +, version $4 \cdot 01$. Values are presented as mean (SD). Data on ischaemia were analysed by the Sign test. Data on ischaemia are presented as medians with ranges, except when otherwise indicated. All $p$ values are derived from two-tailed tests. $\mathrm{p}$ Values $<0.05$ were regarded as significant.

\section{Results}

BASELINE CHARACTERISTICS (TABLE 1)

The mean age of the 10 patients was $61 \cdot 2$ $(10 \cdot 1)$ years. There were three women. All patients had had angina for a mean (SD) of $12.6(9 \cdot 6)$ years. In addition, six had had a myocardial infarction, three had had percutaneous transluminal coronary angioplasty (PTCA) and all patients had coronary artery bypass grafts (CABG).

Four patients had an Itrell I and six had an Itrell II. For patients 1 and 2 we had only one $24 \mathrm{~h}$ ECG recording before SCS. HRV was not analysed in these two patients. The $24 \mathrm{~h}$ recording obtained before implantation of the SCS device was compared with the $24 \mathrm{~h}$ ECG recording when the SCS device was present.

\section{ISCHAEMIA (TABLE 2)}

All ambulatory $48 \mathrm{~h}$ ECG recordings obtained in the 10 patients before SCS showed ST segment changes. During SCS treatment only four patients still had ST changes, and in three of these four the total ischaemic burden, the number of episodes of ischaemia, and their duration were reduced. The total ischaemic burden was reduced in the entire group from a median of $27.9(1.9-278 \cdot 2)$ to $0(0-70 \cdot 2) \mathrm{mm} \times \min (\mathrm{p}<0.03)$. The number of ischaemic episodes was reduced from a median of $3(1-15)$ to $0(0-9)$ with SCS $(\mathrm{p}<0.04)$. The median (range) duration of ischaemia was $20.6(1.7-155.4)$ minutes before SCS and $0(0-48 \cdot 3)$ minutes with SCS $(\mathrm{p}<0.03)$.

\section{GTN INTAKE AND ANGINAL COMPLAINTS} (TABLE 2)

The frequency of anginal attacks dropped from a median of $5.5(2-14)$ before SCS to $1.0(0-10) 48 \mathrm{~h}$ after 6 weeks of SCS treatment $(p<0.03)$. In addition consumption of glyceryl trinitrate in $48 \mathrm{~h}$ decreased from a median of $3.0(0-10)$ tablets per patient to 0.3 $(0-10)(\mathrm{p}<0.02)$

HEART RATES AND ARRHYTHMIAS (TABLE 3)

SCS did not significantly influence the average (mean (SD) $62.0(20.0)$ before SCS and 59.6 (18.5) with SCS), minimal (40.5 (14.4) before SCS and $39.9(13.4)$ with SCS) or maximal (106.9 (33.7) before SCS and 101.8 $(31.7)$ with SCS) heart rate (beats/min) dur-

Table 1 Baseline characteristics

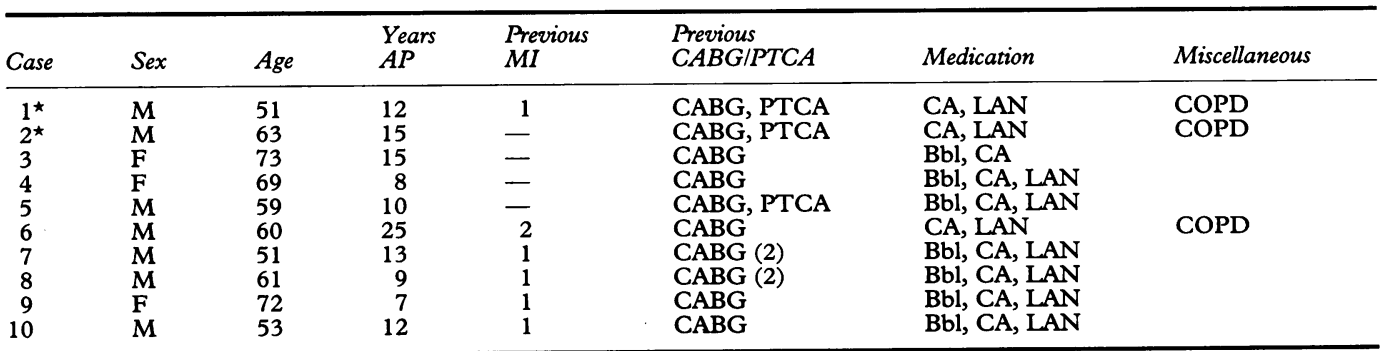

*Only two $24 \mathrm{~h} \mathrm{ECG}$ recording (one before and one during SCS) were available. AP, angina pectoris; Bbl, $\beta$ blockers; CA, calcium antagonist; CABG, coronary artery bypass grafting; COPD, chronic obstructive pulmonary disease; LAN, long acting nitrates; MI, myocardial infarction; PTCA, percutaneous transluminal coronary angioplasty. The patients were not taking digitalis or antiarrhythmic drugs. 
Table 2 Results of $48 \mathrm{~h}$ ambulatory ECG monitoring

\begin{tabular}{|c|c|c|c|c|c|c|c|c|c|c|}
\hline \multirow[b]{2}{*}{ Case } & \multicolumn{2}{|l|}{$T I B$} & \multicolumn{2}{|l|}{$I B E p$} & \multicolumn{2}{|l|}{ IB Dur } & \multicolumn{2}{|l|}{$A A / 48 h$} & \multicolumn{2}{|c|}{$G T N / 48 h$} \\
\hline & $S C S-$ & SCS+ & SCS- & SCS+ & SCS- & SCS+ & SCS- & SCS+ & SCS- & SCS+ \\
\hline $1^{*}$ & 1.9 & 0 & 1 & 0 & $1 \cdot 7$ & 0 & 14 & 4 & 4 & 1 \\
\hline $2^{*}$ & $111 \cdot 5$ & $26 \cdot 6$ & 3 & 3 & 35.0 & $16 \cdot 9$ & 8 & 10 & 8 & 10 \\
\hline 3 & $18 \cdot 4$ & $40 \cdot 3$ & 3 & 4 & $21 \cdot 3$ & $27 \cdot 8$ & 5 & 0 & 1 & 0 \\
\hline 4 & $25 \cdot 7$ & 0 & 3 & 0 & $15 \cdot 1$ & 0 & 6 & 4 & 2 & 0 \\
\hline 5 & $30 \cdot 0$ & 0 & 5 & 0 & $19 \cdot 9$ & 0 & 10 & 5 & 10 & 5 \\
\hline 6 & $278 \cdot 2$ & $17 \cdot 2$ & 15 & 4 & 155.4 & $14 \cdot 8$ & 7 & 1 & 8 & 0 \\
\hline 7 & $10 \cdot 6$ & 0 & 2 & 0 & $9 \cdot 0$ & 0 & 11 & 1 & 0 & 0 \\
\hline 8 & $47 \cdot 0$ & 0 & 8 & 0 & 33.9 & 0 & 5 & 1 & 1 & 0 \\
\hline 9 & $174 \cdot 0$ & $70 \cdot 2$ & 12 & 9 & $81 \cdot 0$ & $48 \cdot 3$ & 2 & 1 & 1 & 0 \\
\hline 10 & 6.9 & 0 & 1 & 0 & $3 \cdot 2$ & 0 & 2 & 0 & 2 & 0 \\
\hline Median & $27 \cdot 9^{\star}$ & $0^{\star}$ & $3+$ & of & $20 \cdot 6 \ddagger$ & $0 \ddagger$ & $5 \cdot 5 \S$ & $1 \cdot 0 \S$ & $3.0 \S$ & $0 \cdot 3 \S$ \\
\hline (range) & $(1 \cdot 9-278 \cdot 2)$ & $(0-70 \cdot 2)$ & $(1-15)$ & $(0-9)$ & $(1 \cdot 7-155 \cdot 4)$ & $(0-48 \cdot 3)$ & $(2-14)$ & $(0-10)$ & $(0-10)$ & $(0-10)$ \\
\hline
\end{tabular}

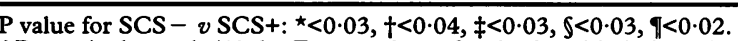

$\mathrm{AP}$, anginal attacks $/ 48 \mathrm{~h}$; Ep, number of episode with ischaemia; Dur, duration (min); GTN, glyceryl trinitrate intake/48 h; TIB, total ischaemic burden $(\mathrm{mm} \times \mathrm{min})$.

ing ambulatory ECG recording. Analysis of the $48 \mathrm{~h}$ ECG recordings showed no influence of SCS on supraventricular or ventricular extrasystoles or arrhythmias.

HEART RATE VARIABILITY (TABLE 3)

HRV was analysed before and with SCS in eight patients. There was a slight increase in the coefficient of variance but this was not statistically significant. In all eight patients HRV was moderately reduced or normal, as expressed by the standard deviation of the intervals (SDNN) and by the coefficients of variance.

\section{DURATION OF STIMULATION}

The mean duration of stimulation (SD) assessed by telemetry was $3 \cdot 1(0 \cdot 2) \mathrm{h}$ during the first week after implantation and $3 \cdot 2(0 \cdot 3) \mathrm{h}$ after 6 weeks.

\section{Discussion}

ALTERATIONS IN THE ST SEGMENT DURING AMBULATORY ECG RECORDING

Studies in the 1970 s established the accuracy and significance of standardised ambulatory ECG recordings of both silent ischaemia and painful ischaemia during daily activity. ${ }^{12} 13$ and

Table 3 Heart rate, arrhythmia, and heart rate variability

\begin{tabular}{lcc}
\hline & Before SCS & With SCS \\
\hline No QRS/48 h & $166 \cdot 037(45 \cdot 824)$ & $159 \cdot 894(45 \cdot 871)$ \\
HR minimum & $40 \cdot 5(14 \cdot 4)$ & $39 \cdot 9(13 \cdot 4)$ \\
HR mean & $62(20 \cdot 0)$ & $59 \cdot 6(18 \cdot 5)$ \\
HR maximum & $106 \cdot 9(33 \cdot 7)$ & $101 \cdot 8(31 \cdot 7)$ \\
VE & $1258(7-4236)$ & $1401(8-5639)$ \\
VE couplets & $76(0-444)$ & $51(0-265)$ \\
VE run & $4(0-17)$ & $1(0-8)$ \\
SVES & $120(20-709)$ & $74(0-335)$ \\
SVES couplets & $4(0-9)$ & $8(0-60)$ \\
SVES run & $5(0-40)$ & $2(0-8)$ \\
Mean NN interval (SD) & $959(107)$ & $994(123)$ \\
SD per 5 min period & $37(15)$ & $35(17)$ \\
SDNN & $103(33)$ & $115(33)$ \\
SDNN/mean NN $(\approx C V)$ & $10(15)$ & $11(19)$ \\
SDANN & $93(29)$ & $91(29)$ \\
rMSSD & $23(8)$ & $25(6)$ \\
pNN50 & $5(5)$ & $5(3)$ \\
$0.01-1 \cdot 0$ (TP) & $21(11)$ & $25(8)$ \\
$0 \cdot 04-15$ (LF) & $12(8)$ & $14(6)$ \\
$0 \cdot 15-0 \cdot 4$ (HF) & $8(4)$ & $9(3)$ \\
LF (nu) & $30(9)$ & $31(12)$ \\
HF (nu) & $14(4)$ & $14(7)$ \\
\hline
\end{tabular}

There were no statistically significant differences between the two groups. CV, coefficient of variance; couplets, two consecutive extrasystoles; HF, high frequency; LF, low frequency; NN,
mean of all coupling intervals between normal beats; SD, standard deviation; SDNN, standard mean of all coupling intervals between normal beats; SD, standard deviation; SDNN, standard $\%$ of adjacent NNs $\geqslant 50 \mathrm{~ms}$ different; rMSSD, root mean square of difference of successive $\%$ of adjacent NNs $\geqslant 50 \mathrm{~ms}$ different; rMSSD, root mean square of difference of successive
NNs; run, $\geqslant 3$ consecutive SVES or VEs; SVES, supraventricular extrasystole; VE, ventricular NNs; run, $\geqslant 3$ consecutive SVES or VEs; SVES,
extrasystole; TP, total power (see text for details). the correlation between ST segment shifts on ambulatory ECG recording and coronary artery disease. ${ }^{14}$ The relation between ST segment shifts on ambulatory ECG monitoring and regional myocardial ischaemia was validated by physiological radioisotopic studies in patients with known coronary artery disease. ${ }^{1516}$ Both the frequency and duration of ischaemia on ambulatory ECG recording correlated with physical activity and mental stress levels. ${ }^{17}$ Nonetheless there was also dayto-day variability in myocardial ischaemia. ${ }^{18} 19$

Does a reduction in ST depression, assessed during ambulatory ECG monitoring, alter the prognosis of patients with coronary artery disease? The answer seems to depend on the risk of an adverse cardiac event..$^{2021} \mathrm{We}$ know of no other reports of prognosis in patients with intractable angina. Despite the improvement in exercise capacity, SCS did not seem to increase the occurrence of myocardial ischaemia and patients remained aware of the angina though the pain was reduced. Therefore, we do not expect SCS to worsen prognosis.

Changes in $48 \mathrm{~h}$ ECG monitoring produced by SCS during the unrestricted activities of normal life are unlikely to be due to chance alone. There is likely to be considerable variation in ambulatory ECGs between patients which is why in this study of SCS each patient acted as his or her own control.

\section{AMBULATORY ST SEGMENT RECORDING}

DURING SPINAL CORD STIMULATION

To date ambulatory ECG monitoring is the best tool to evaluate myocardial ischaemia during daily life. During SCS, however, artefacts interfere with the ambulatory ECG recording. Fortunately, in our study the frequency content of the ST segment was below the cut off point of the $\mathrm{KH}$ low pass filter and the analysis of the ST segment was not hampered by the low pass filter. ${ }^{22}$ The significant improvement in the indices of ischaemia and symptoms that we showed in this study could be the result of an analgesic effect of SCS and an anti-ischaemic effect of SCS.

\section{ANALGESIC EFFECT OF SCS}

In 1967 Wall and Sweet reported that electrostimulation had an analgesic effect that was 
sustained after stimulation stopped. ${ }^{2}$ Though intermittent SCS may not have the same effects on myocardial ischaemia as does continuous SCS, both stimulation regimens had beneficial effects. ${ }^{5-9}$

Transmission of the nociceptive cardiac signal to the CNS is mediated by slowly conducting $\mathrm{A} \delta$ fibres and by even more slowly conducting $\mathrm{C}$ fibres. These afferent fibres run in parallel with the sympathetic (mainly epicardial) and parasympathetic (mainly endocardial) nerves from different regions in the heart to the dorsal column of the spinal cord (fig 1). Sensory pain fibres of the heart project to cells at (T1-T5) level in the spinal cord. These cells are the origin of the spinothalamic tract. This classic pain pathway can relay pain stimuli to centres such as the thalamus and limbic system. These centres connect with the somatosensible cortex, the level at which an individual becomes aware of the nociceptive stimulus. Descending pathways from the limbic portion of the brain control the cardiovascular system to ensure the survival of the individual.

According to the so-called gate control model $^{1}$ stimulation of the dorsal spinal cord (SCS) can interrupt transmission of several types of (visceral) pain, such as angina. According to the hypothesis, transmission of pain from $\mathrm{C}$ fibres and $\mathrm{A} \delta$ fibres to the substantia gelatinosa gate cells of the dorsal horn can be modulated. In addition, a higher central decoding mechanism can exert descending control on this gate setting. It has been known for a long time that stimulation of certain limbic structures alters coronary blood flow. ${ }^{23}$ These structures can modulate the sympathetic tone of the coronary arteries.

Because the transmission time of the impulses during SCS is too fast to explain persistence of the effect after stimulation has stopped, mechanisms other than the gate control theory must be involved. There is evidence of resetting within spinothalamic cells. ${ }^{24}$ The modulation of these cells could be caused by neurohumoral compounds released through neurostimulation. ${ }^{25}$

\section{ANTI-ISCHAEMIC EFFECT OF SPINAL CORD STIMULATION}

Mannheimer et al and Sanderson et al reported a significant decrease in ST depression during SCS in patients with therapeutically refractory angina. ${ }^{89}$ These groups assessed ischaemic indices at comparable workloads during exercise tests. The finding in our ambulatory ECG study of a decrease in ischaemic indices with SCS in nine out of 10 patients with otherwise intractable angina is consistent with the reduction of exerciseinduced myocardial ischaemia with SCS. However, only four patients in our study had five or more episodes of ischaemia during the $48 \mathrm{~h}$ ambulatory ECG monitoring before SCS.

In our study SCS was used intermittently three times a day for up to an hour each time. We found that this protocol abolished ischaemia in six patients during the hours that
SCS was not used. Ischaemia was reduced in three of the remaining four patients.

The potential for rebound ischaemia to develop, for instance after exercise, when SCS is temporarily withheld, must have been counterbalanced by the sustained anti-ischaemic influence, that we found in this study. Thus SCS is likely to be safe. In addition, the significant reduction in myocardial ischaemia by SCS in this study was accompanied by a significant decrease in angina symptoms (angina attacks and glyceryl trinitrate intake).

Mechanism of anti-ischaemic action-It is not clear whether SCS reduces ischaemia by reducing myocardial oxygen consumption (as proposed by Mannheimer ${ }^{26}$ ) or by improving oxygen supply. The first mechanism is supported by a decrease in heart rate during SCS in an experimental study. ${ }^{27}$ This decrease in heart rate may counteract the increase in heart rate during ischaemic episodes. ${ }^{28}$ Increased parasympathetic activity or reduced sympathetic activity might explain the reduction in heart rate by SCS. We studied the possible alteration in the balance of the autonomic system caused by SCS by assessing HRV during the ambulatory ECG recording. We used Marquette HRV software version 2A for this analysis.

A decreased HRV was associated with the severity of ischaemic heart disease ${ }^{29}$ and with an increased risk in sudden death. ${ }^{30}$ The patients in our study had moderately decreased to normal HRV, expressed as the SDNN of the normal intervals (table 3). In our study SCS did not influence HRV indices consistently. This may reflect the small sample size and method used. Moreover, we did not find a consistent effect of SCS on the minimum, average, or maximal heart rates.

Because all our patients had advanced intractable coronary artery disease and were on optimal medication, the reduction in myocardial ischaemia without any effect on the heart rate suggests an improved oxygen supply to the heart. This may be by redistribution of coronary blood flow.

In patients with severe peripheral vascular disease spinal cord stimulation enhanced the impaired blood flow in the affected limb, however, in patients with coronary artery disease positron emission tomography did not show redistribution of coronary blood flow. ${ }^{31}$

\section{COSTS AND COMPLICATIONS}

SCS is expensive. None the less, some of our patients have returned to work and hospital admissions were reduced for most of the patients. A less expensive, but possibly comparable, therapy is transcutaneous electrical nerve stimulation (TENS). TENS was also effective in patients with intractable angina. ${ }^{32}$ With TENS, however, patients have to carry an external device, and have irritating electrodes on their chests and batteries that run out more quickly.

On the other hand, SCS is associated with a relatively high rate of (micro)-dislocation of the lead, which requires reprogramming or sometimes reoperation. 
Before these techniques become widely used, both cost benefit and mortality studies are essential.

LIMITATION OF THE STUDY

Because the patients feel the stimulation and the stimulation artefacts are apparent on the ECG it is impossible to design a double blind study. Further studies are required to evaluate the relation between the duration of the antiischaemic effect and the duration of stimulation.

CONCLUSION

Our ambulatory ECG study showed that SCS significantly reduced both myocardial ischaemia and symptomatic ischaemia, expressed as a significant decrease in total ischaemic burden, duration of ischaemia, and number of ischaemic episodes and reduction of anginal attacks and glyceryl trinitrate intake. This study confirmed that SCS is a safe adjuvant treatment for patients with otherwise intractable angina.

We thank Mr Pieter de Jonge, Mrs Inge ten Vaarwerk, Mrs Johanna F Westerhoek, Mr Rudy van der Meer, and Mr Arnold Dijk for support and technical advice.

The Netherlands Heart Foundation funded this study

1 Melzack R, Wall PD. Pain mechanisms: a new theory Science 1965;150:971-9.

2 Wall PD, Sweet WH. Temporary abolition of pain in man Science 1967;155:108-9.

3 Shealy CN, Mortimer JT, Reswick JB. Electrical inhibition of pain by stimulation of the dorsal columns. Anesth Analg 1967;46:489-91.

4 Eriksson MBE, Sjölund BH, Nielzen S. Long term results of peripheral conditioning stimulation as an analgesic measure in chronic pain. Pain 1979;6:335-47.

5 González-Darder JM, Canela P, González-Martinez V. High cervical spinal cord stimulation for unstable angina pectoris. Stereotact Funct Neurosurg 1991;56:20-7.

6 Murphy DF, Giles KE. Dorsal column stimulation for pain relief from intractable angina pectoris. Pain 1987, 28:365-8.

7 Jongste de MJL, Aerts A, Bouwmeester TR, Kloppenburg W, Meyler WJ, Mulder P, Staal MJ, Zijlstra G, Lie KI. Spinal cord stimulation as an adjuvant therapy for otherwise intractable severe angina pectoris [abstr]. $¥ \mathrm{Am} \mathrm{Coll}$ wise intractable severe angina
Cardiol 1992;19(suppl 3):87A.

8 Mannheimer C, Augustinsson LE, Carlsson CA, Manhem $\mathrm{K}$, Wilhelmsson C. Epidural spinal electrical stimulation $\mathrm{K}$, Wilhelmsson C. Epidural spinal electrical stimula

9 Sanderson JE, Brooksby P, Waterhouse D, Palmer RBG Neubauer K. Epidural spinal electrical stimulation for severe angina: a study of effects on symptoms, exercise tolerance and degree of ischemia. Eur Heart $\mathcal{f} 1992$ 13:628-33.

10 Cohn PF: Total ischemic burden: pathophysiology and prognosis. Am 7 Cardiol 1987;59:3C-6C.

11 Cohn PF. Total ischemic burden: Definition, mechanisms, and therapeutically implications. Am $f$ Med 1986 81(suppl 4A):2-6.

12 Stern S, Tzivoni D. Dynamic changes in ST-T segment during sleep in ischemic heart disease. Am $\mathcal{f}$ Cardio 1973;32:17-20.

13 Schang SJ, Pepine CJ. Transient asymptomatic S-T seg ment depression during daily activity. $\mathrm{Am} \mathcal{f}$ Cardiol ment depression
14 Stern S, Tzivoni D, Stern Z. Diagnostic accuracy of ambulatory ECG monitoring in ischemic heart disease. Circulation 1975;52:1045-9.

15 Selwyn AP, Allen R, L'abbote L, Horlock P, Comici $P$, Clarck J, O'Brien H, Grant PM. Relationship between regional myocardial uptake of rubidium-82 and perfusion: Absolute reduction of cation uptake in ischemia. Am $₹$ Cardiol 1982;50:112-21.

16 Deanfield JE, Shea $M$, Ribiero $P$, deLandsheere $C M$ Wilson RA, Horlock P, Selwyn AP. Transient ST segment depression as a marker of myocardia ischemia during daily life. $A m \mathcal{F}$ Cardiol 1984;54: 1195-200.

17 Barry J, Selwyn AP, Nabel EG, Rocco MB, Mead K, Campbell S, Rebecca G. Frequency of ST-segmen depression produced by mental stress in stable angin pectoris from coronary artery disease. $A m \mathcal{F}$ Cardio 1988;61:989-93.

18 Tzivoni D, Gavish A, Benhorin J, Banai S, Keren A, Stern S. Day-to-day variability of myocardial ischemic episodes in coronary artery disease. $\mathrm{Am} f$ Cardiol 1987;60:1003-5.

19 Nabel EG, Barry J, Rocco MB, Campbell S, Mead K, Fenton T, Orav EJ, Selwyn AP. Variability of transient myocardial ischemia in ambulatory patients with coromary artery disease. Circulation 1988;78:60-7.

20 Nademanee K, Intarachot V, Josephson MA, Rieders D Vaghaiwalla Mody F, Singh BN. Prognostic significance of silent myocardial ischemia in patients with unstable of silent myocardial ischemia in patie.

21 Quyyumi AA Panza JA, Diodati JG, Callahan TS, Bonow RO, Epstein SE. Prognostic implications of myocardial ischemia during daily life in low risk patients with coronary artery disease. $\mathcal{F}$ Am Coll Cardiol 1993;21 $700-8$.

22 Tayler DI, Vincent R. Artefactual ST segment abnormalities due to electrocardiographic design. Br Heart 1985;54:121-8.

23 Ueda $H$, Shimomura $K$, Goto $H$, Yasuda $H$, Ito $K$, Katayama S, Kuroiwa A, Sugimoto T. Changes in coronary blood flow by stimulation of central nervous system. Fap Heart $\mathcal{F}$ 1964;5:323-36.

24 Foreman RD. Viscerosomatic convergence onto spinal neurons responding to afferent fibers located in the inferior cardiac nerve. Brain Res 1977;137:164-8.

25 Sjölund BH, Eriksson MBE. Endorphins and analgesia produced by peripheral conditioning stimulation. In: produced by peripheral conditioning stimulation. In: Bonica J, Liebeskind JC, AlbeFessard DG, eds. Advances in pain research

26 Mannheimer C, Waagstein F, Eliasson $T$, Berg $\mathrm{CH}$ Andersson B, Augustinsson LE, Emanuelsson H. Spinal cord stimulation in pacing-induced angina pectori [abstr]. F Am Coll Cardiol 1993;21 (suppl A):785.

27 Meglio M, Cioni B, Rossi GF, Sandric S, Santarelli P. Spinal cord stimulation affects the central mechanism of regulation of heart rate. Appl Neurophysiol 1986;49: $139-46$.

28 Deedwania PC, Nelson JR. Pathophysiology of silent myocardial ischemia during daily life. Hemodynamic evaluation by simultaneous electrocardiographic and blood pressure monitoring. Circulation 1990;82: 1296-304.

29 Hayano J, Sakakibara Y, Yamada M, Ohte N, Fujinami T, Yokoyama K, Watanabe Y, Takata K. Decreased magnitude of heart rate spectral components in coronary artery tude of heart rate spectral components in coronary artery disease. Its relation

30 Kleiger RE, Miller JP, Bigger JT, Moss AJ and the Multicenter post-infarction research group. Decreased Multicenter post-infarction research group. Decreased
heart rate variability and its association with increased heart rate variability and its association with increased mortality after ac

31 Landsheere $\mathrm{CH}$ de, Mannheimer C, Habets A, Guillaume M, Bourgeois I, Augustinsson LA, Eliasson T, Lamotte D, Kulbertus H, Rigo P. Effect of spinal cord stimulation on regional myocardial perfusion assessed by positron emission tomography. Am f Cardiol 1992;69: 1143-9.

32 Mannheimer C, Carlson CA, Emanuelsson H, Vedin A, Waagstein $F$, Wilhelsson $C$. The effects of transcutaneous electrical nerve stimulation in patients with sever angina pectoris. Circulation 1985;71:308-16. 